\title{
Prognostic indicators and the pattern of recovery of communication in aphasic stroke patients
}

\author{
MARY J PICKERSGILL, NADINA B LINCOLN
}

\begin{abstract}
From the Department of Psychology, Bedford College, London and the Department for the Health Care of the Elderly, Sherwood Hospital, Nottingham, UK
\end{abstract}

SUMMARY Communication abilities were assessed on a wide range of tests in 56 aphasic stroke patients, 33 classified as "moderate" and 23 as "severe". Thirty-six of the patients had received language treatment. The biographical variables of age, months post-onset and handedness were shown to be differentially correlated with improvements. In particular, there were some significant trends of decreasing improvement with increasing months post-onset on expressive verbal tasks in treated moderate aphasics and on comprehension tasks in treated severe aphasics. Untreated patients did not show the same clear pattern of trends; however, these patients were reassessed after a shorter period and covered a smaller range of months post-onset. The role of treatment deserves further clarification. The results also indicate that language recovery is relatively independent of age and of handedness.

It is accepted that some recovery of language function occurs spontaneously following the onset of aphasia and there is some knowledge of its course and duration. Studies have been conducted to determine prognostic indicators of response to language treatment but more rarely of spontaneous recovery in untreated patients. However, the extent to which such treatment significantly affects the course of recovery remains controversial ${ }^{1-3}$ and it may be that indicators of spontaneous recovery and of response to treatment will not be easily distinguishable. Aphasia of traumatic origin has been shown to have a better prognosis than that of vascular origin ${ }^{4}{ }^{5}$ but, since in both studies the groups were different in age, with the traumatic aphasics being younger, age may have been the relevant factor rather than aetiology. Age has been reported as an important prognostic indicator with older patients having a worse prognosis $^{6} 7$ but more recent studies on treated and untreated patients have failed to support those findings although the full range has been covered. $^{58-10}$ Neither finding a significant relationship nor the failure to do so appears to depend on the ages of the samples investigated.

More recovery is found to occur early after onset,

Address for reprint requests: Dr MJ Pickersgill, Bedford College, Regent's Park, London NW1 4NS, UK.

Received 8 June 1982

Accepted 30 September 1982 particularly in the first three months. ${ }^{50-12}$ It is generally considered to continue for between three and six months, though longer intervals, such as eight months ${ }^{13}$ and eight years ${ }^{14}$ have been suggested. However, variability in intervals between assessments and in criteria for change causes problems in comparing studies. The pattern of recovery has also been investigated but results are not consistent: some studies $^{10}{ }^{13} 1516$ report greater improvement in receptive, others ${ }^{17}$ in expressive abilities. The position is summarised by Marshall18 as one of "no real agreement . . . on the seemingly simple question of whether the prognosis for expressive skills is better or worse than that for comprehension". Kenin and Swisher ${ }^{15}$ related improvement to severity of damage; while all patients tended to improve, it was noted that the most impaired patients improved much less.

Handedness has also been considered relevant and the incidence of aphasia is higher in left-handed stroke patients than right-handed. ${ }^{19}{ }^{20} \mathrm{Smith}^{21}$ found that fewer left-handed stroke patients had chronic aphasia and Luria, quoted by Zangwill, ${ }^{22}$ found similarly in cases of trauma that a severe residual aphasia was rare in left- and mixed-handedness while it occurred in three quarters of the pure righthanders. These findings would support the idea that left-handers have bilateral representation of speech and, therefore, would be more prone to suffer aphasia but would recover faster or more completely. However, there are problems in assessing handed130 
ness in an aphasic population: many have a hemiplegia, rendering performance tasks inappropriate, whereas questionnaire items cannot be answered by those with comprehension problems.

Prognostic indicators of response to language treatment have practical implications for clinical work, particularly since, as Geschwind ${ }^{14}$ points out, "Although spontaneous useful recovery therefore occurs in many cases, we should not forget that poor recovery is still the fate of possibly the majority of patients". Various treatments have been found not to have a significant effect on recovery of groups of patients but they may be of benefit to individual patients. It is therefore desirable to predict who would benefit from treatment in order for resources to be appropriately allocated. Prognostic indicators of spontaneous recovery might indicate which patients were likely to recover without specific intervention, allowing treatment to be directed to those who would not otherwise recover.

\section{Method}

The study was designed to investigate factors affecting response to language treatments given at a rehabilitation centre and recovery of language in a group of general hospital patients receiving no specific language rehabilitation programme. The factors under consideration were age, months post-onset and handedness. Three groups of aphasic stroke patients were assessed on two occasions. Two of the groups consisted of patients attending Rivermead Rehabilitation Centre and receiving individual language treatments. The third group consisted of patients receiving no individual language-treatment programme who were in general hospitals.

\section{Patient samples}

Group 1 consisted of 24 moderately aphasic stroke patients. All patients referred to the Speech Therapy Department of Rivermead Rehabilitation Centre, Oxford, between December, 1973, and December, 1977, with aphasia following a cerebral vascular accident (CVA) were assessed for inclusion in a language treatment trial. ${ }^{1}$ Patients had no previous history of brain damage and were expected to attend the Centre for at least 8 weeks. Their aphasia had to be of a degree for which both treatments (speech therapy and an operant technique), would be appropriate and, on these grounds, both severely and minimally aphasic patients were excluded. The inclusion criteria were mean scores on the Porch Index of Communicative Ability (PICA) ${ }^{23}$ of 14 or less on test IV, eight or more on tests VI and X, seven or more on test IX and 10 or more on test XII. ${ }^{23}$ In practice, this was between approximately the 35 th and 65 th percentiles on the PICA Overall score. There were 142 patients initially referred. Of these, $37 \mathrm{met}$ the criteria for inclusion. Of those excluded, 51 were too severely aphasic, 35 too minimally aphasic and 21 were excluded on the basis of the other criteria before they were classified. The sample was therefore selected from the patients initially referred to. provide a basis for fair evaluation of the therapies. Of the 37 patients suitable for the treatment trial, 13 failed to complete treatment and therefore had to be excluded. These patients left the unit because of home-sickness and further illness; none left on account of complete recovery. However, no criteria were set in terms of dyspraxia, mood or concomitant intellectual deficits since this would have resulted in even fewer patients being available for inclusion.

Group 2 consisted of 12 severely aphasic stroke patients who were included in a treatment trial of operant training (Note 1), having been first admitted to the Rehabilitation Centre in the same way as patients in Group 1 . All scored below 8 on PICA tests VI and X, below 7 on test IX and below 10 on test XII, were below the 35th percentile and had been rejected for Group 1 as too severe.

Group 3 consisted of 20 aphasic stroke patients referred to the Occupational Therapy departments of hospitals in the Oxford Region. At these hospitals they received no or very little speech therapy and were employed in the treatment trial as an "untreated" control group. When a hospital notified the admission of a patient, similar assessment procedures were carried out to those of Groups 1 and 2 and the patient was subsequently classified as "moderate" or "severe". The criteria were the same except that tests VI and $\mathrm{X}$ were not included. At the time of first assessment, all patients had been admitted to the hospital but by the time of their reassessment some were attending as out-patients. The selection of patients for inclusion in this group was discontinued when speech therapy services were increased in each of the hospitals concerned but, until that time, all aphasic CVA patients were referred for assessment. Patients aged over 69 years, however, were excluded in order not to have an upper age limit higher than that within the treated groups.

The characteristics of the Groups at first assessment are shown in table 1 . There is a greater proportion of males in the treated than the untreated groups of both the moderately and the severely aphasic patients. The difference is not significant on a two-tailed test of $\chi^{2}, p>0.05$. The specialist unit had twice as many male as female beds, reflecting its policy of offering rehabilitation to resume employment. Age is closely comparable in all groups both in mean and range. Untreated aphasics are about one month nearer onset but the main difference on this factor is in the range of months post onset, this being more restricted in the untreated group. Of a total of 56 patients, 55 are right handed for writing and have more than $50 \%$ right handedness on a Laterality Index assessing handedness on a range of items.

\section{Period between assessments}

Patients in Groups 1 and 2 were assessed in their first week of admission to a rehabilitation centre. Both of the groups were taking part in experiments to evaluate the effects of various treatments ${ }^{1}$ (Note 1 ). In neither group was any specific treatment found to be of advantage and it was therefore decided to use the final reassessment at the end of eight weeks as the best available indicator of recovery. Patients in Group 3 were assessed at general hospitals in the Occupational Therapy departments. Testing was carried out when the occupational therapists considered a patient could tolerate a session about an hour long. They were reassessed four weeks later. 
Table 1 Group characteristics at first assessment

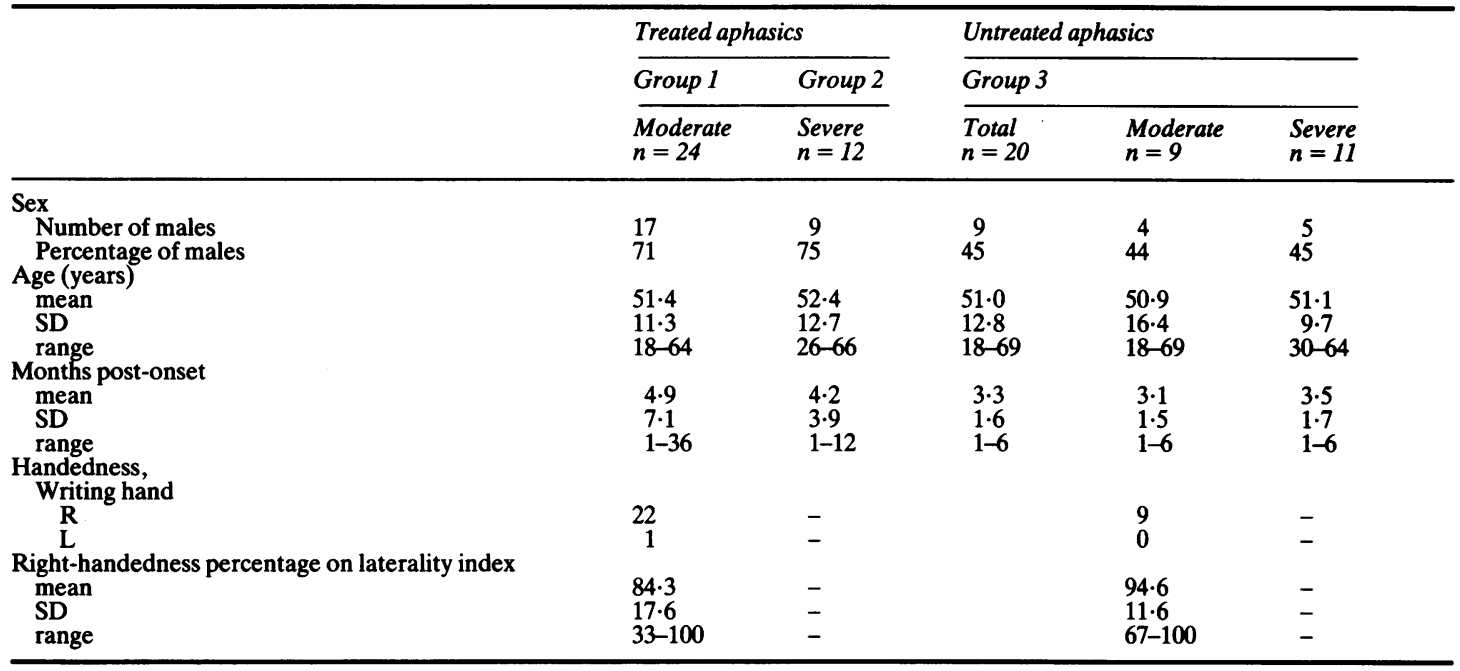

- not assessed; the handedness of one patient was not assessed.

\section{Assessments}

The main test employed was the Porch Index of Communicative Ability (PICA). This was administered to Groups 1 and 2 by an experienced speech therapist and re-administered by the same therapist. As less time was available for assessing Group 3 patients, only the Verbal Scale (tests I, IV, IX and XII) of the PICA was employed and (as no speech therapists were available) it was administered on both occasions by a clinical psychologist (NBL). The PICA consists of a battery of 18 subtests sampling gestural, verbal and graphic abilities at various levels of difficulty and chosen to sample various input and output modalities. Since the battery is intended to sample basic communication ability, the complexity of the tasks is not demanding in terms of intelligence, education or experience. The tests are ordered from the most difficult to the least difficult, thus reducing the effect of immediate recall and encouraging the patient, since the modalities being sampled are changed frequently. Scoring is on a 16 point multidimensional scale, based on five dimensions of describing a response: accuracy, responsiveness, completeness, promptness and efficiency. The scoring system devised by Porch attempts to relate these five dimensions at a workable level for each point on the scale. The range of task difficulty is satisfactory but there is some loss of discrimination at the higher levels. The advantages of the PICA are good standardisation and reliability, and sensitivity to small changes in abilities. There are, however, some doubts as to whether the 16 category multidimensional scale should be treated as interval, ordinal or nominal. ${ }^{24}$

In addition, some further tests from the following list were given to all groups by the clinical psychologist:

Edinburgh Handedness Inventory ${ }^{25}$

Token Test ${ }^{26}$ (Note 2)

Oldfield-Wingfield Object Naming Test ${ }^{27}$

Fluency (number of items of food and countries of the world named in two minutes each)
Picture Description (number of different words used to describe a picture)

Eisenson: Visual Agnosia for colours, shapes and pictures ${ }^{28}$ scored on the PICA multidimensional scale sc $^{23}$

Peabody Picture Vocabulary, first 50 items $^{29}$

Progressive Matrices ${ }^{30}$

Self Rating (Note 2)

Speech Questionnaire (Note 2) completed by a nurse, a physiotherapist and an occupational therapist.

Reassessment was carried out by the same assessor on all items, except for the Edinburgh Handedness Inventory which was not repeated. Only Group 2 and the moderate aphasics in Group 3 were assessed on the Edinburgh Handedness Inventory as the test was often not feasible for the severe aphasics. There were other differences in the tests administered. The Fluency and Picture Description tests were dropped for Group 2, which was tested after Groups 1 and 3, as it was by then realised that these also were inappropriate for severe aphasics. Instead, Group 2 was given the Eisenson Visual Agnosia and the Peabody Picture Vocabulary tests. Group 3 was not tested on the Speech Questionnaire since the relevant staff members (nurse, physiotherapist and occupational therapist) would rarely have been in a position to complete it for both assessments.

\section{Results}

The means and standard deviations of test scores on each occasion for each group are shown in table 2 . There are significant changes $(p<0.05)$ on a twotailed test on 28 out of 32 measures in Group 1 and on 11 out of the 12 measures in the moderate aphasics in Group 3. The severely aphasic patients in Group 2 show significant change on only 19 out of 34 and those 
Table 2 Means and standard deviations of test scores for the three groups of aphasic patients

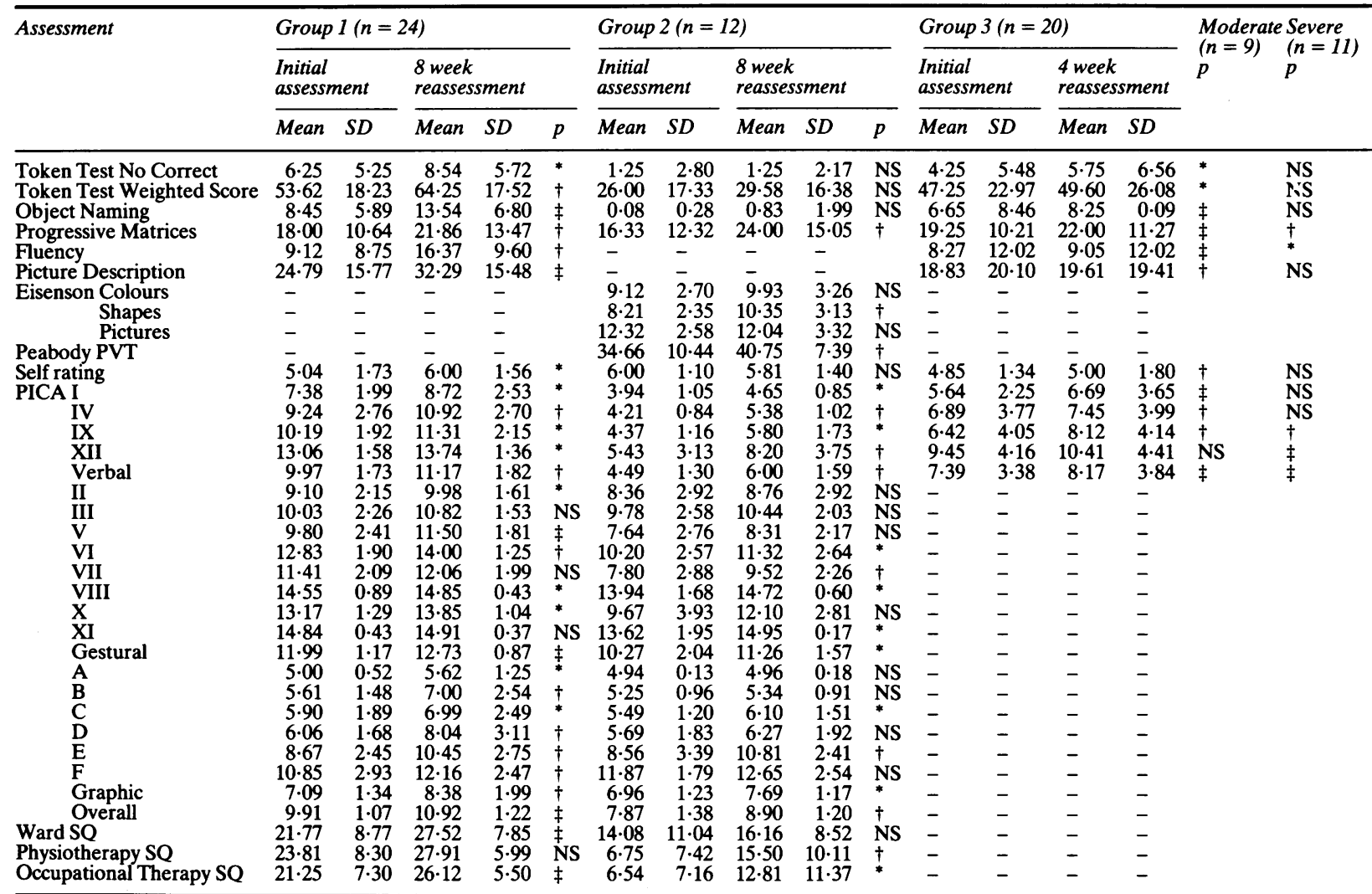

- not administered; SQ - Speech Questionnaire; ${ }^{*}$ p $<0.05$ (two-tailed); $\nmid p<0.01$ (two-tailed); $\ddagger$ p $<0.001$ (two-tailed).

$p$ values were calculated separately for moderate and severe patients in Group 3 and are shown in separate columns.

in Group 3 on 5 out of 12 measures. All significant changes are in the direction of improvement. Although a few assessments differ between the groups, it seems possible to infer that the moderate patients are somewhat more likely than the severe ones to show improvement. This inference would be consistent with the finding by Kertesz and $\mathrm{McCabe}^{5}$ of a significant positive correlation between initial severity and outcome. The further conclusion, that the picture is not changed by treatment, has been supported by relevant statistical analysis of the treatment effects ${ }^{1}$ (Note 1) and would also be consistent with the tentative conclusions of Kertesz and McCabe, ${ }^{5}$ based on a comparison of treated and untreated global aphasics only.

\section{Age}

The correlations (Pearson product moment) between age and change in ability on each assessment for each group are shown in table 3 . One-tailed tests of significance have been applied since previous work suggests that if there is a relationship it will be between increase in age and smaller improvements, that is the correlations will be negative. Correlations are all non-significant except three: in Group 1, younger patients improved more on the Progressive Matrices ( $p<0.05)$, in Group 2, on the Speech Questionnaire rated by physiotherapists $(p<0 \cdot 01)$ and, in Group 3, on the PICA test IV, naming objects $(\mathrm{p}<0 \cdot 05)$. Generally, the results indicate little relation between age and improvement in ability. However, in Group 2, the severe aphasics, there are about twice as many negative correlations as positive; this is also the only group in which the average correlation is negative $(-0.08$, compared with 0.11 in Group 1 and 0.06 in Group 3), possibly suggesting that increased age is more likely to be associated with lack of improvement in severe than in moderate aphasia. Of course, it may not be appropriate to consider the correlations as independent but, since 
Table 3 Pearson product moment correlations between increase in age and improvement in ability

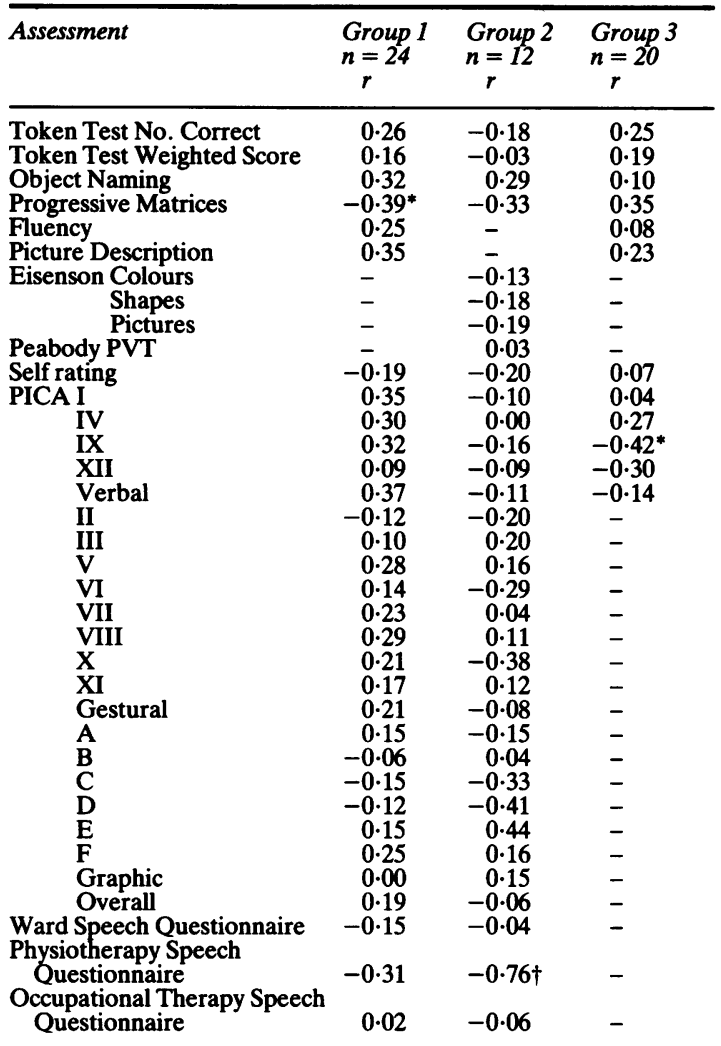

- not assessed

${ }^{*} \mathrm{p}<0.05$ (one-tailed).

$+\mathrm{p}<0.01$ (one-tailed).

the assessments were chosen to sample as wide a range of communication and language abilities as possible, they should be relatively so.

\section{Months post-onset}

Correlations (Pearson product-moment) between months post-onset at first assessment and change in ability on each assessment for the three groups are shown in table 4. Since the expectation from previous work is that improvement will be greater the nearer to onset the assessment, one-tailed tests have again been employed.

Correlations are mostly nonsignificant though seven are significant at the 0.05 and two at the 0.01 level. This is unlikely to be a chance finding due to the number of correlation coefficients calculated since, out of 78 correlations, 65 are similarly negative. Overall average correlations are $-\mathbf{0 . 1 3}$ for Group 1 , -0.28 for Group 2 and -0.12 for Group 3. The pattern is much the same in all groups, implying that treatment strategy has no effect, but it may be worth noting that the relation tends to be stronger in the severe than in the moderate treated group.

The correlations carried out were designed to detect a linear relationship between two variables. However, examination of the data suggested that, where there were large improvements, they were greatly concentrated in the early months post-onset. It was decided to test also for trend using Jonckheere's distribution free $k$-sample test against ordered alternatives, ${ }^{31}$ a test sensitive to any monotonic relationship, whether or not linear. The expectation is that there will be decreasing improvement with increasing months post-onset at first assessment and one-tailed tests have been applied. All the $z$ scores have been quoted but in some cases the large number of ties makes a trend test somewhat inappropriate. These are usually where there is no change in many of the patients in one of the severe

Table 4 Pearson product moment correlations between increase in months post-onset and improvement in ability

\begin{tabular}{|c|c|c|c|}
\hline Assessment & $\underset{\substack{\text { Group } \\
r=24}}{r}$ & $\underset{\substack{\text { Group } \\
r}}{2} 2$ & 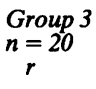 \\
\hline $\begin{array}{l}\text { Token Test No Correct } \\
\text { Token Test Weighted Score } \\
\text { Object Naming } \\
\text { Progressive Matrices } \\
\text { Fluency } \\
\text { Picture Description } \\
\text { Eisenson Colours } \\
\quad \text { Shapes } \\
\quad \text { Pictures } \\
\text { Peabody PVT } \\
\text { Self rating } \\
\text { PICA I } \\
\text { IV } \\
\text { IX } \\
\text { XII } \\
\text { Verbal } \\
\text { II } \\
\text { III } \\
\text { V } \\
\text { VI } \\
\text { VII } \\
\text { VIII } \\
\text { X } \\
\text { XI } \\
\text { Gestural } \\
\text { A } \\
\text { B } \\
\text { C } \\
\text { D } \\
\text { E } \\
\text { F } \\
\text { Graphic } \\
\text { Overall } \\
\text { Ward Speech Ouestionnaire }\end{array}$ & $\begin{array}{l}-0.33 \\
-0.20 \\
-0.53 \dagger \\
0.00 \\
-0.10 \\
-0.20 \\
- \\
- \\
- \\
- \\
-0.04 \\
-0.33 \\
-0.31 \\
-0.36^{*} \\
0 \cdot 06 \\
-0.31 \\
-0.03 \\
-0.01 \\
-0.35^{*} \\
-0.12 \\
-0.24 \\
-0.19 \\
-0.13 \\
-0.09 \\
-0.22 \\
-0.21 \\
-0.21 \\
-0.12 \\
-0.21 \\
0.02 \\
-0.12 \\
-0.16 \\
-0.27 \\
0.06\end{array}$ & $\begin{array}{l}-0.52^{*} \\
-0.58^{*} \\
-0.26 \\
-0.35 \\
- \\
- \\
-0.25 \\
-0.58^{*} \\
-0.07 \\
-0.29 \\
0.12 \\
-0.39 \\
-0.45 \\
-0.26 \\
-0.31 \\
-0.40 \\
-0.34 \\
-0.35 \\
-0.04 \\
-0.17 \\
0.00 \\
-0.44 \\
-0.10 \\
-0.49 \\
-0.35 \\
-0.28 \\
-0.13 \\
-0.26 \\
-0.45 \\
-0.53^{*} \\
-0.02 \\
-0.39 \\
-0.41 \\
-0.30\end{array}$ & $\begin{array}{l}-0 \cdot 28 \\
-0 \cdot 48^{*} \\
-0 \cdot 01 \\
-0 \cdot 32 \\
-0 \cdot 40 \\
0 \cdot 24 \\
- \\
- \\
- \\
- \\
-0 \cdot 55 \dagger \\
-0 \cdot 11 \\
0 \cdot 10 \\
-0 \cdot 08 \\
0 \cdot 14 \\
0 \cdot 03 \\
- \\
- \\
- \\
- \\
- \\
- \\
- \\
- \\
- \\
- \\
- \\
- \\
- \\
- \\
- \\
- \\
- \\
-\end{array}$ \\
\hline $\begin{array}{l}\text { Physiotherapy Speech } \\
\text { Questionnaire } \\
\text { Occupational Therapy Speech } \\
\text { Questionnaire }\end{array}$ & $\begin{array}{c}0.05 \\
-0.35^{*}\end{array}$ & 0.40 & - \\
\hline
\end{tabular}

- not assessed.

* $\mathrm{p}<0.05$ (one-tailed)

$\dagger \mathrm{p}<0.01$ (one-tailed). 
Table $5 z$ Scores from Jonckheere's tests for trend in the direction of lesser change with greater months post-onset

\begin{tabular}{|c|c|c|c|c|c|}
\hline \multirow[t]{3}{*}{ Assessment } & \multicolumn{2}{|c|}{ Treated aphasics } & \multicolumn{3}{|c|}{ Untreated aphasics } \\
\hline & \multirow{2}{*}{$\begin{array}{c}\text { Group } 1 \\
\begin{array}{c}\text { Moderate } \\
(n=24) \\
z\end{array}\end{array}$} & \multirow{2}{*}{$\begin{array}{l}\text { Group 2 } \\
\begin{array}{l}\text { Severe } \\
(n=12) \\
z\end{array}\end{array}$} & \multicolumn{3}{|l|}{ Group 3} \\
\hline & & & $\begin{array}{l}\text { Total } \\
\begin{array}{c}(n=20) \\
z\end{array}\end{array}$ & $\begin{array}{c}\text { Moderate } \\
(n=9) \\
z\end{array}$ & $\begin{array}{c}\text { Severe } \\
(n=11) \\
z\end{array}$ \\
\hline $\begin{array}{l}\text { Token Test No Correct } \\
\text { Token Test Weighted Score } \\
\text { Object Naming } \\
\text { Progressive Matrices } \\
\text { Fluency } \\
\text { Picture Description } \\
\text { Eisenson Colours } \\
\text { Shapes } \\
\quad \text { Pictures } \\
\text { Peabody PVT } \\
\text { Self rating } \\
\text { PICA I } \\
\text { IV } \\
\text { IX } \\
\text { XII } \\
\text { Verbal } \\
\text { II } \\
\text { III } \\
\text { V } \\
\text { VI } \\
\text { VII } \\
\text { VIII } \\
\text { X } \\
\text { XI } \\
\text { Gestural } \\
\text { A } \\
\text { B } \\
\text { C } \\
\text { D } \\
\text { E } \\
\text { F } \\
\text { Graphic } \\
\text { Overall } \\
\text { Ward Speech Questionnaire } \\
\text { Physiotherapy Speech Questionnaire } \\
\text { Occupational Therapy Speech Questionnaire }\end{array}$ & $\begin{array}{l}1.80^{*} \\
0.99 \\
3.43 \ddagger \\
-0.87 \\
2.31 \dagger \\
2.24^{*} \\
- \\
- \\
- \\
- \\
0.51 \\
2.49 \dagger \\
2.57 \dagger \\
3.08 \ddagger \\
-0.41 \\
2.82 \dagger \\
-0.36 \\
0.36 \\
1.63 \\
0.38 \\
1.78^{*} \\
1.27 \\
1.22 \\
-0.13 \\
0.58 \\
1.12 \\
1.58 \\
0.33 \\
1.04 \\
1.12 \\
0.97 \\
0.99 \\
1.88^{*} \\
0.33 \\
2.44 \dagger \\
1.96^{*}\end{array}$ & $\begin{array}{l}0.98 \\
2.18^{*} \\
0.77 \\
0.84 \\
- \\
1.33 \\
1.33 \\
2.04^{*} \\
0.56 \\
1.61 \\
-0.63 \\
0.84 \\
1.82^{*} \\
1.75^{*} \\
0.63 \\
1.47 \\
1.19 \\
0.91 \\
0.42 \\
0.21 \\
0.49 \\
2.25^{*} \\
2.88 \dagger \\
2.25^{*} \\
1.75^{*} \\
0.21 \\
0.35 \\
1.05 \\
1.26 \\
1.54 \\
1.40 \\
1.96^{*} \\
2.18^{*} \\
1.33 \\
0.35 \\
0.56\end{array}$ & $\begin{array}{c}1.00 \\
1.70^{*} \\
-0.47 \\
0.96 \\
1.33 \\
-0.39 \\
- \\
- \\
- \\
- \\
0.63 \\
1.46 \\
0.10 \\
0.00 \\
-0.50 \\
0.03\end{array}$ & $\begin{array}{c}-0.32 \\
-0.43 \\
0.00 \\
0.75 \\
1.61 \\
-0.86 \\
- \\
- \\
- \\
- \\
-0.32 \\
0.65 \\
-1.18 \\
1.18 \\
-0.43 \\
0.11\end{array}$ & $\begin{array}{c}1.67^{*} \\
2.54^{*} \\
-0.24 \\
0.48 \\
-0.32 \\
0.86 \\
- \\
- \\
- \\
\overline{1} \\
1.75 \\
1.51 \\
1.67 \\
-0.79 \\
-0.16 \\
0.24\end{array}$ \\
\hline
\end{tabular}

* $\mathrm{p}<0.05$ (one-tailed)

$+\mathrm{p}<0.01$ (one-tailed)

$\ddagger \mathrm{p}<0.001$ (one-tailed).

- not assessed.

groups on a given measure. The proportion of ties is about $20 \%$ of the observations in the predicted direction on the following: Group 1, PICA VIII, PICA XI; Group 2, Token Test (Number Correct), Object Naming, PICA I, PICA VIII, PICA A, PICA B, PICA C, PICA D and Occupational Therapy Speech Questionnaire; Group 3 (Combined), Token Test (Number Correct), Object Naming, Fluency and Self rating; Group 3 (moderate aphasics), Object Naming; Group 3 (severe aphasics), Object Naming, Fluency and Picture Description. Of these, only one test, PICA VIII in Group 2, gives a significant result and the general conclusions are, therefore, not materially affected. The results are shown in table 5.

In the treated groups, 22 out of $66 \mathrm{z}$ scores are significant, 8 of these with $p<0 \cdot 01$. In the total group of untreated aphasics, one $z$ score out of 12 is significant. Taking separately the moderate and severe untreated groups, there is no significant trend in the moderate aphasics and only two in the severe aphasics (one with $\mathrm{p}<0.01$ ). This difference between the treated and untreated groups may be related to the fact that change in the untreated aphasics was assessed over a period of four, as opposed to eight, weeks. However, significant improvements occurred in both the severe and the moderate untreated aphasics and, as the extent of improvement in the untreated groups was similar to that in the treated groups, it appears that the shorter period between assessments has not prevented the appearance of similar trends through restriction of the range of improvement scores. Again, the chance of establishing trends in the untreated groups may have been limited by their relatively restricted range of months post-onset but, as most recovery occurs early and as all the patients are between one and six months post-onset, this is probably not the case. The difference between treated and untreated groups in 
the strength of association between months postonset and improvement presumably fails to be apparent in the correlations because the association is a nonlinear one, to which the Pearson product moment correlation is relatively insensitive.

\section{Pattern of recovery}

Moderate aphasics in Group 1 but not in Group 3 show significant trends of decreasing change with increasing months post-onset on expressive verbal tasks (table 5). Only PICA Test VII, a test of reading ability, shows a significant trend but does not involve expressive verbal abilities. This result suggests that expressive verbal abilities recover over time and the improvement decreases with increase in months postonset. This recovery could be spontaneous or a nonspecific response to treatment, given that the different treatments investigated were shown not to have a differential effect on recovery. ${ }^{1}$ Since the untreated moderate aphasics in Group 3 did not show a similar pattern of recovery of expressive verbal abilities, the latter possibility would seem the more likely.

Severe aphasics in Group 2 show significant trends of increasing change with decrease in months postonset mainly on comprehension tasks, that is Token Test weighted score, Eisenson shapes, Peabody PVT, PICA X, XI and the Gestural Scale. In addition, one expressive verbal task, PICA IV, naming objects, showed a significant correlation. These results also could be due to a nonspecific effect of receiving some treatment. However, since untreated severe aphasics in Group 3 show a significant trend on the Token Test scores, and the other comprehension items were not administered to this group, they are also consistent with the interpretation that comprehension shows recovery which is "spontaneous", that is time related but independent of treatment.

\section{Handedness}

Handedness could only be assessed adequately for the moderately aphasic patients. Pearson productmoment correlations between change scores and Handedness Indices $\left(\frac{R}{R+L} \times 100\right)$ are shown in table 6 . One-tailed tests have been applied, left-handers being expected to improve more (indicated by negative correlations).

Generally, results indicate no significant relation between left-handedness, as measured on the Edinburgh Handedness Inventory, and improvement in ability. Most correlations ( 35 out of 44 ) are in the opposite direction to that predicted and may suggest that recovery tends to be better in patients with more strongly lateralised handedness. However, only one patient is left-handed on the Edinburgh Inventory in
Table 6 Pearson product moment correlations between Edinburgh Handedness Inventory scores and improvement in ability

\begin{tabular}{|c|c|c|}
\hline Assessment & $\begin{array}{l}\text { Group } 1 \\
(n=24) \\
r\end{array}$ & $\begin{array}{l}\text { Group } 3 \\
\text { Moderate aphasics } \\
(n=9) \\
r\end{array}$ \\
\hline $\begin{array}{l}\text { Token Test No. Correct } \\
\text { Token Test Weighted Score } \\
\text { Object Naming } \\
\text { Progressive Matrices } \\
\text { Fluency } \\
\text { Picture Description } \\
\text { Self rating } \\
\text { PICA I } \\
\text { IV } \\
\text { IX } \\
\text { XII } \\
\text { Verbal } \\
\text { II } \\
\text { III } \\
\text { V } \\
\text { VI } \\
\text { VII } \\
\text { VIII } \\
\text { X } \\
\text { XI } \\
\text { Gestural } \\
\text { A } \\
\text { B } \\
\text { C } \\
\text { D } \\
\text { E } \\
\text { F } \\
\text { Graphic } \\
\text { Overall } \\
\text { Ward Speech Ouestionnaire }\end{array}$ & $\begin{array}{r}0 \cdot 36 \\
0 \cdot 30 \\
0 \cdot 26 \\
0 \cdot 31 \\
0 \cdot 12 \\
0 \cdot 40 \\
0 \cdot 17 \\
0 \cdot 24 \\
0 \cdot 05 \\
0 \cdot 23 \\
0 \cdot 55 \\
0 \cdot 32 \\
-0 \cdot 01 \\
0 \cdot 07 \\
-0 \cdot 33 \\
0 \cdot 07 \\
0 \cdot 18 \\
0 \cdot 17 \\
-0 \cdot 03 \\
0 \cdot 37 \\
-0 \cdot 03 \\
0 \cdot 36 \\
0 \cdot 37 \\
0 \cdot 38 \\
0 \cdot 24 \\
0 \cdot 30 \\
0 \cdot 12 \\
0 \cdot 12 \\
0 \cdot 27 \\
0 \cdot 37\end{array}$ & $\begin{array}{r}-0.03 \\
0.03 \\
0.12 \\
-0.03 \\
-0.05 \\
0.04 \\
-0.03 \\
0 \cdot 12 \\
0 \cdot 16 \\
-0.38 \\
0.72 \\
0 \cdot 13 \\
- \\
- \\
- \\
- \\
- \\
- \\
- \\
- \\
- \\
- \\
- \\
- \\
- \\
- \\
- \\
- \\
-\end{array}$ \\
\hline $\begin{array}{l}\text { Ward Speech Questionnaire } \\
\text { Physiotherapy Speech } \\
\text { Questionnaire } \\
\text { Occupational Therapy } \\
\text { Speech Questionnaire }\end{array}$ & $\begin{array}{r}0.37 \\
-0.07 \\
0.06\end{array}$ & - \\
\hline
\end{tabular}

All correlations are nonsignificant at the $5 \%$ level (one-tailed test). - not assessed.

the sense of having a quotient below $50 \%$ and this patient is also the only one to be left-handed for writing. Thus, it is not possible fully to test the hypothesis that recovery is better in clinically assessed left-handers. No common element can be detected in the tasks which show the highest correlations. PICA Test XII, repetition of object names, gives the strongest correlation in both groups tested, but seems to have no distinguishing feature.

\section{Discussion}

These results show varying degrees of relation between age, months post-onset and handedness with improvement in abilities. The sample of patients selected is likely to be more homogeneous than the total aphasic population and relatively little variation is likely, thus possibly limiting the range of correlations. The ages considered, for example, are relatively young since the majority of stroke patients are over 65 years. However, Kertesz and McCabe, ${ }^{5}$ 
with a much wider age range, also found a nonsignificant negative correlation of age with initial recovery rates. Again, more than half of the patients were recent aphasics, that is 1 to 3 months post-onset at first assessment. Handedness also was not widely distributed since no strongly left-handed patients were included. This problem of few left handers is likely to occur in any sample of this size.

The direction of correlation between changes and months post-onset is consistent with expectation and significant trends also occurred on several tests. Inspection of the data suggests that, consistent with the results of other workers, most recovery occurs in the period 1 to 4 months post-stroke (no patients were seen at less than one month post-stroke) and thereafter few changes occur. Because of restrictions in the range of months post-onset in Group 3 and of the shorter period between assessments, it is not possible to be certain that the significant trends observed to a greater extent in the treated Groups 1 and 2 are in fact dependent on the (nonspecific) response to treatments rather than being based on spontaneous recovery. However, for reasons given earlier, it is thought that the different pattern found in the treated groups should not be dismissed on methodological grounds. It would be a point worth settling since, should it be shown that these trends do exist in treated groups only, it would be implied not only that without treatment recovery occurs more slowly and in more even steps, albeit to the same extent, but also that treatment needs to be given as soon as possible after a stroke in order to achieve its maximum effect; in other words, language treatment early after onset may hasten recovery but not extend the degree of recovery finally achieved.

Hagen's study ${ }^{3}$ demonstrates some significant effects of treatment on both expressive and receptive abilities. As all his patients entered treatment or control conditions at the same point after onset and, as the interaction was not partitioned in such a way as to establish the temporal location of the treatment effect, it is not possible to determine statistically whether degree of within-group improvement is related to months post-onset. However, Hagen concludes from the graphs that the major effects in the treated group had occurred during the first 6 months of therapy. With respect to the relatively uncommon finding that treatment improves performance, it should be noted that treatment lasted for the unusually long period of one year, from 6 to 18 months post-onset, by which time motivational factors may have been strongly involved, a point we refer to later.

Where there are trends, there seem to be differential effects according to the severity of initial aphasia. Patients who were in the moderate group showed significant trends on mostly expressive verbal tasks, those in the severe group mostly on tasks involving comprehension. This may mean that recovery of comprehension occurs first with expressive abilities recovering later. Then the pattern of recovery would depend on the severity of initial language impairment with the ceiling for recovery from severe aphasia being too low to permit the recovery of expressive abilities, at least in the time available. Correspondingly, the moderate aphasics in Group 1 may have already completed most of their recovery on comprehension, where few changes were to be observed, but would have had room to improve their performance on tests of expressive abilities.

Thus, we are suggesting a relation between the severity of aphasia and the difficulty levels of the tasks examining it, these being associated with the types of ability tested, that is expressive verbal or comprehension. Assuming an underlying dimension of severity would lead to the expectation, consistent with our results, of a predictable course of recovery through different types of abilities, in particular receptive before expressive. Such an interpretation may appear somewhat unsubtle in its approach to the pattern of recovery, given the complexities of known aphasic syndromes, but may nevertheless help to resolve some of the uncertainties referred to earlier. ${ }^{18}$ The implication of an underlying severity dimension is consistent with the re-interpretation of Schuell's ${ }^{32}$ seven categories of aphasia recently offered by Powell et al ${ }^{33}$ on the basis of a cluster-analysis of the scores of 86 aphasics on Schuell's test.

There is an additional problem when interpreting differences between trends in severe and moderate aphasics on the PICA. Lincoln et $a l^{24}$ found that judged intervals between PICA scores are not always equal. If severe aphasics have to improve over large gaps on expressive tasks and small gaps on comprehension tasks, a trend may be apparent in the latter only, whereas if moderate aphasics are improving over small gaps on expressive tasks then trends may become apparent on these tasks. Strictly speaking, therefore, different patterns of results from moderate and severe aphasics are not directly comparable. However, conclusions relating to significant trends within groups are likely to remain valid.

It has been noted that the results on handedness do not show the expected correlation between lefthandedness and greater improvement. Other workers, however, have found this relationship. The restriction of the handedness range may be the reason our results contribute little to support their findings, but they may also sound a note of caution against concluding either that the relation between handedness and recovery from aphasia is readily 
predictable or that some degree of left-handedness is any protection against the effects of a stroke.

It may be that other variables would have been more suitable predictors of recovery. Since differences were found between the recovery patterns of severe and moderate aphasics it seems at least likely that initial severity of aphasia may predict rate of recovery at different stages. There are problems with determining whether this is the case, again because the measures used need to be interval scales, with change scores on one part of a scale being comparable to changes on another. The betweengroups comparison of improvements assessed from different starting points has always been a problem for clinical studies and one to which there seems no completely satisfactory answer.

Motivation appears clinically to be an important determinant of recovery. One of the problems is how to assess it. Patients who were reported by staff to be highly motivated also said they were keen to get better, practised language tasks on their own, asked to be given work to do alone and showed concern over their own progress. Recording of these behaviour patterns might be used as a preliminary investigation of motivational factors.

The present results also have implications for the mechanisms of recovery. These, of course, remain obscure. It has been pointed out, for example, that, where recovery takes place, its rate is incompatible with new language learning. Our results indicate that the course of recovery is not even over time, particularly in treated groups, where it appears that improvements on many measures are occurring in the first four months post-onset, with little thereafter. Explanations such as removal of right hemisphere suppression $^{34}$ or the physiological recovery of spared neural tissue ${ }^{35}$ may be sufficient to account for such a time course, albeit not very explicitly. Where, on the other hand, as was much more often the case in untreated groups, recovery is equally likely to occur at any stage, then this seems to be more likely to be due to behavioural strategy changes. ${ }^{36}$ It may be worth devising measures to probe for adaptive strategies which could have occurred independently of formal therapy but which may all the same have resulted in significant gains in communication skills.

We thank Miss CR Hilton, LCST, and Mrs AI Hankey, LCST, for assessing patients on the PICA and Dr C Westropp, Dr CD Evans, Dr E Rushworth, Dr BK Samtami and Dr T Davidson, Consultant Physicians, for permission to see their patients.

\section{Reference Notes}

1. Lincoln NB, Pickersgill MJ. The effectiveness of programmed instruction and operant training in the language rehabilitation of severely aphasic patients. (1982). (Submitted for publication).

2. Lincoln NB. (1979) An investigation of the effectiveness of language treatment methods with aphasic stroke patients. Unpublished PhD thesis, University of London.

\section{References}

${ }^{1}$ Lincoln NB, Pickersgill MJ, Hankey AI, Hilton CR. An evaluation of operant training and speech therapy in the language rehabilitation of moderate aphasics. Behavioural Psychotherapy 1982;10:162-78.

${ }^{2}$ Meikle M, Wechsler E, Tupper A, et al. Comparative trial of volunteer and professional treatments of dysphasia after stroke. Br Med J 1979;2:87-9.

${ }^{3}$ Hagen C. Communication abilities in hemiplegia: effect of speech therapy. Arch Phys Med Rehabil 1973;54:454-63.

${ }^{4}$ Butfield E, Zangwill OL. Re-education in aphasia: a review of 70 cases. J Neurol Neurosurg Psychiatry 1946;9:75-9.

${ }^{5}$ Kertesz A, McCabe P. Recovery patterns and prognosis in aphasia. Brain 1977;100:1-18.

6 Vignolo LA. Evolution of aphasia and language rehabilitation: a retrospective exploratory study. Cortex 1964;1:344-67.

${ }^{7}$ Sands E, Sarno MT, Shankweiller D. Long term assessment of language function in aphasia due to stroke. Arch Phys Med Rehabil 1969;50:202-6.

${ }^{8}$ Sarno MT, Silverman M, Levita E. Psychological factors and recovery in geriatric patients with severe aphasia. $J$ Am Geriatr Soc 1970;18:405-9.

${ }^{9}$ Keenan JS, Brassel EG. A study of factors related to prognosis for individual aphasic patients. $J$ Speech Hear Disord 1974;39:257-69.

${ }^{10}$ Basso A, Capitani E, Vignolo LA. Influence of rehabilitation on language skills in aphasic patients-a controlled study. Arch Neurol 1979;36:190-6.

${ }^{11}$ Culton GL. Spontaneous recovery from aphasia. J Speech Hear Res 1969;12:825-32.

${ }^{12}$ Sarno MT, Levita E. Natural course of recovery in severe aphasia. Arch Phys Med Rehabil 1971;52:175-9.

${ }^{13}$ Hanson WR, Cicciarelli AW. Time, amount and pattern of language improvement in adult aphasics. $\mathrm{Br} J$ Disord Commun 1978;13:59-63.

${ }^{14}$ Geschwind N. Late changes in the nervous system: an overview. In: Stein DG, Rosen JJ, Butters N, eds. Plasticity and Recovery of Function in the Central Nervous System. New York: Academic Press, 1974:467-508.

${ }^{15}$ Kenin M, Swisher LP. A study of pattern of recovery in aphasia. Cortex 1972;8:56-68.

${ }^{16}$ Prins RS, Snow CE, Wagenaar E. Recovery from aphasia: spontaneous speech versus language comprehension. Brain Lang 1978;6:192-211.

${ }^{17}$ Lomas J, Kertesz A. Patterns of spontaneous recovery in aphasic groups: a study of adult stroke patients. Brain Lang 1978;5:388-401.

${ }^{18}$ Marshall JC. Acquired Disorders of Language. In: Jeeves MA, ed. Psychology Survey No. 3. London: George Allen and Unwin, 1980: Ch5, 62-78.

${ }^{19}$ Subirana $A$. The prognosis in aphasia in relation to 
cerebral dominance and handedness. Brain 1958;81:415-25.

${ }^{20}$ Brown JR, Simonson J. A clinical study of 100 aphasic patients. Neurology (Minneap) 1957;7:777-83.

${ }^{21}$ Smith A. Objective indices of severity of chronic aphasia in stroke patients. J Speech Hear Disord 1971;36:167207.

${ }^{2}$ Zangwill OL. Cerebral Dominance and its Relation to Psychological Function. Edinburgh: Oliver and Boyd, 1960.

${ }^{23}$ Porch BE. Porch Index of Communicative Ability. Palo Alto: Consulting Psychologists Press, 1967.

${ }^{24}$ Lincoln NB, Pickersgill MJ, Valentine JD. Is the PICA an equal interval scale? $\mathrm{Br} J$ Disord Commun 1982;16:185-91.

${ }^{25}$ Oldfield RC. The assessment and analysis of handedness: the Edinburgh Inventory. Neuropsychologia 1971;9: 97-113.

${ }^{26}$ DeRenzi E, Vignolo LA. The Token Test: a sensitive test to detect receptive disturbances in aphasics. Brain 1962; 85:665-78.

${ }^{27}$ Oldfield RC, Wingfield A. A series of pictures for use in object naming. Oxford: MRC Psycholinguistics Research Unit, Special Report No. PLU/65/19, 1965.
${ }^{28}$ Eisenson J. Examining for Aphasia. New York: Psychological Corporation, 1954.

${ }^{29}$ Dunn LM. Peabody Picture Vocabulary Test: Expanded Manual. Minneapolis: American Guidance Service, 1965.

${ }^{30}$ Raven JC. Standard Progressive Matrices. London: Lewis, 1958.

${ }^{31}$ Jonckheere AR. A distribution free k-sample test against ordered alternatives. Biometrika 1954;41:133-45.

${ }^{32}$ Schuell H. Minnesota Test for the Differential Diagnosis of Aphasia. Minneapolis: University of Minnesota, 1965.

${ }^{33}$ Powell GE, Clark E, Bailey S. Categories of aphasia: a cluster-analysis of Schuell test profiles. $\mathrm{Br} J$ Disord Commun 1979;14:111-22.

${ }^{34}$ Geschwind N. Disorders of higher cortical function in children. Clinical Proceedings Children's Hospital National Medical Center 1972;28:261-72.

${ }^{35}$ Braun JJ. Time and Recovery from Brain Damage. In: Finger S, ed. Recovery from Brain Damage. New York: Plenum Press, 1978:165-94.

${ }^{36}$ Gazzaniga MS. Is seeing believing: notes on clinical recovery. In: Finger S, ed. Recovery from Brain Damage. New York: Plenum Press, 1978;409-14. 